
\title{
$\begin{array}{ll}\text { Research Square } & \begin{array}{l}\text { Preprints are preliminary reports that have not undergone peer review. } \\ \text { They should not be considered conclusive, used to inform clinical practice, } \\ \text { or referenced by the media as validated information. }\end{array}\end{array}$
}

\section{The Diagnostic Role of Sputum miRNA in Non-Small Cell Lung Cancer}

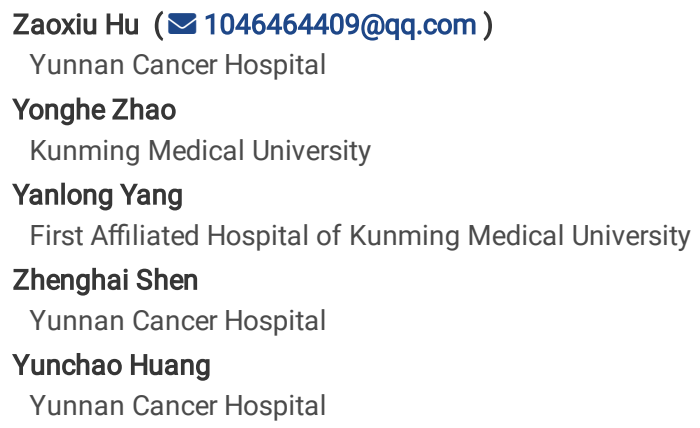

\section{Research article}

Keywords: sputum miRNA, non-small cell lung cancer, diagnostic value,biomarker

Posted Date: August 24th, 2020

DOI: https://doi.org/10.21203/rs.3.rs-62275/v1

License: () (7) This work is licensed under a Creative Commons Attribution 4.0 International License. Read Full License 


\section{Abstract}

Objective: Recent studies indicated sputum miRNAs may provide a promising approach for non-small cell lung cancer (NSCLC) diagnosis. But some results were still inconsistent. So, we performed meta-analysis to evaluate the diagnostic role of sputum miRNAs for the detection of NSCLC.

Methods: Eligible studies that estimated the diagnostic accuracy of sputum miRNAs in NSCLC were searched in Pubmed, Embase and Web of Science and Chinese National Knowledge Infrastructure (CNKI). Data from the eligible studies were collected and pooled; sensitivity, specificity, positive and negative likelihood ratios, diagnostic odds ratios, weighted symmetric summary ROC curve and the area under the curve (AUC) were calculated by bi-variate random effects model. The between-study heterogeneity was evaluated by $Q$ test and $\mathrm{I}^{2}$ statistics.

Results: 30 studies from 16 articles were included for analysis. The overall analysis yielded the sensitivity of 0.77 (95\% Cl: $0.73-0.81)$ and specificity of 0.87 (95\% Cl: $0.83-0.90)$, with an area under the SROC curve (AUC) of 0.89 ( $95 \% \mathrm{Cl}: 0.86-0.91$ ). Subgroup analysis revealed the diagnostic accuracy in multiple miRNAs studies was higher than single miRNA (the sensitivity, specifcity and an AUC of multiple miRNAs were 0.76, 0.88 and 0.90; and for single miRNA, it was $0.74,0.74$, and 0.80 ). The diagnostic performance in early stage NSCLC was also very high (the sensitivity, specifcity and an AUC of stage I/II was 0.76 , 0.88 and 0.91 ; and for stage $\mathrm{I}$, it was $0.79,0.85$, and 0.87 ). We also found miR-210, miR-21, miR-31 and miR-126-3p might serve as potential biomarkers for lung cancer.

Conclusion: Sputum miRNAs was useful noninvasive biomarkers for NSCLC diagnosis.

\section{Introduction}

Lung cancer still remains the most common cancer and the most common cause of cancer-related death worldwide. ${ }^{1}$ Lung cancer is the most common incident cancer and the leading cause of cancer death in China in $2015 .^{2}$ In Untied State, Lung cancer is estimated the second common cancer and the first leading causes of cancer death in $2017 .{ }^{3}$ About $80 \%$ lung cancers were non-small cell lung cancer (NSCLC). ${ }^{4}$ As the typically asymptomatic at early stages, most patients with NSCLC were diagnosis at locally advanced or metastatic disease. The 5 -year survival rate for stage IV NSCLC is only $10 \%$, whereas it is approximately $80 \%$ for stage IA. ${ }^{5}$ Improve the early detection of lung cancer is very necessary and important to improve the prognosis of patients with lung cancer.

Low-dose CT (LDCT) is commonly used in lung cancer screening. Early detection of lung cancer using LDCT has demonstrated in a large randomized trial a $20 \%$ reduction in mortality in heavy smokers as compared to chest X-rays. ${ }^{6}$ However, this strategy has several limitations including high false-positive rates, potential over-diagnosis, excessive cost and the potential harm associated with radiation exposure. ${ }^{7}$ Existing protein biomarkers such as carcinoembryonic antigen (CEA) and CYFRA21-1 did not show sufficient sensitivity and specificity. ${ }^{8}$ Therefore, it is important to develop early detection methods to reduce lung cancer-related deaths.

Sputum contains exfoliated airway epithelial cells, it is the most easily accessible biological fluid ${ }^{9}$. In recent years, sputum cytological analysis has been used for lung cancer diagnosis. Sputum cytology can identify morphologic abnormalities of bronchial epitheliums of patient with lung cancer, but poor sensitivity was exhibited. Molecular study of sputum could detect the cells containing lung tumor-associated molecular aberrations, thus providing a noninvasive approach for diagnosis of lung cancer. ${ }^{10,11}$

MicroRNAs (miRNAs) are short (typically 18-25 nucleotides), single-stranded and highly conserved non-coding RNAs which could negatively regulate gene expression at post-transcriptional level by binding the 3'-untranslated region of target mRNAs, resulting in either mRNA degradation or translational repression. Dysregulation of miRNAs plays crucial roles in tumorigenesis. Specific over or under expressions of miRNAs have been found to associate with particular tumor types, and thus open up a new field for molecular diagnosis of cancer. ${ }^{12}$ Many studies suggested that miRNAs are stably present in sputum, and aberrant miRNA expression could be potentially useful for lung cancer diagnosis. ${ }^{11,13}$ Although studies have indicated that various sets of miRNAs can be used as highly sensitive and specific markers for the detection of LC. However, conflicting results are still present due to the limited sample size and static power in individual study. Therefore, a systematic analysis of these data may be valuable to further explore the clinical applicability of miRNAs as biomarkers for the diagnosis of lung cancer.

\section{Methods}

\section{Literature search}

A comprehensive literature search was conducted in the databases of PubMed, EMBASE and Web of Science and Chinese National Knowledge Infrastructure (CNKI). The last search time was Nov 28, 2018. The following terms and combinations were used to identify studies: "microRNA", "miRNA", "lung cancer" and "lung neoplasm". Furthermore, references of retrieved articles and reviews were manually screened for additional studies.

\section{Eligibility Criteria}

The inclusion criteria were applied to identify the eligible studies: (1) articles with full texts published in English and Chinese; (2) studies investigated the diagnostic role of sputum miRNAs in NSCLC; (3) provided the diagnostic gold standard for confirming NSCLC; (4) provided sufficient data for the construction of two-by-two tables, including true positive (TP), false positive (FP), true negative (TN), and false negative (FN). The exclusion criteria were as the follows: (1) 
publications unrelated to the diagnostic values of circulating miRNAs for lung cancer; (2) studies with duplicate data reported in other studies; (3) letters, editorials, case reports or reviews.

\section{Data Extraction And Quality Assessment}

The data and information, including the name of first author, year of publication, country of study, characteristics of participants (sample size, ethnicity) were sorted. Sensitivity, specificity, TP, FP, TN and FN were extracted from included studies. The quality of each eligible study was assessed by the revised Quality Assessment of Diagnostic Accuracy Studies tool. ${ }^{14}$

\section{Statistical analysis}

STATA 12.0 software (StataCorp, College Station, TX, USA) is used to perform the statistical analyses. Bivariate regression model was used to calculate the pooled sensitivity, specificity, positive likelihood ratio (PLR), negative likelihood ratio (NLR) and diagnostic odds ratio (DOR). The DOR is an indicator of test performance. Area under the curve (AUC) was calculated to evaluate the diagnostic accuracy of miRNA in discriminating NSCLC patients from controls. The summary receiver operator characteristic (SROC) curve was plotted based on the sensitivity and specificity. ${ }^{15,16}$ The $\mathrm{I}^{2}$ test was conducted to analyze the heterogeneity between studies, which $\mathrm{I}^{2}$ more than $50 \%$ indicated that there is a substantial between-study heterogeneity that existed. ${ }^{17}$ The potential sources of heterogeneity were further identified by subgroup analyses. We assessed the publication bias in included studies by using Deek's funnel plot asymmetry test. $^{18}$

\section{Results}

\section{Eligible studies}

Initial screen identified 37 articles. After reviewing the titles and abstracts, 9 articles were excluded because they obviously did not meet our selection criteria. The remaining 28 articles were further checked by screening the full texts. In this period, 12 studies were excluded because they are reviews or meta-analyses $(n=5)$, insufficiency information $(n=3)$, detecting miRNA methylation $(n=2)$ or data overlapping $(n=2)$. As a result, 16 articles ${ }^{11,13,19-32}$ were eligible for final meta-anlaysis. Figure 1A showed the process of studies identification. Among 16 articles, 6 articles consisted at least 2 independent studies ${ }^{11,19,22,26,27,32}$, as a result, 30 studies from 16 articles including 2,447 subjects (1,212 patients with lung cancer and 1,235 controls) were included for analysis. These studies published from 2010 to 2018, and the sample size ranged from 30 to 315 . Two studies conducted in Asian ${ }^{24,27}$, seven studies conducted in Caucasian ${ }^{13,20,25,28-31}$ and the remaining seven studies ${ }^{11,19,21-23,26,32}$ conducted in mixed population. Two studies ${ }^{19,26}$ selected healthy population as controls, 11 studies $^{13,20-23,25,28-32}$ selected cancer-free subjects as controls, and the remaining three studies ${ }^{11,24,27}$ applied benign pulmonary disease (BPD) as controls. The detailed information of the included articles was listed in Table 1. Quality assessments results for each eligible study according to QUADAS-2 guidelines are presented in Figure 2B.

\section{Pooled Diagnostic Accuracy of miRNA}

The overall predictive accuracy of miRNAs was summarized in Table 1 . The pooled sensitivity was 0.77 (95\% Cl: $0.73-0.81)$, the specificity was $0.87(95 \%$ Cl: 0.83-0.90) (Figure 2), the pooled PLR was 5.9 (95\% Cl: 4.7-7.4), the NLR was 0.26 (95\% Cl: 0.22-0.30) and the DOR of 23 (95\% Cl: 18-29) (Table 2). The AUC value was 0.89 ( $95 \% \mathrm{Cl}: 0.86-0.91)$, and the corresponding SROC curve was shown in Figure $3 \mathrm{~A}$. The Fagan diagram was also applied to illustrate the posttest probabilities of sputum miRNAs in lung cancer diagnosis (Figure 3B).

\section{Subgroup analyses}

Various subgroup analyses according to race, miRNA profiling, source of control, histology type, sample size, publication year and stage were done. The results were summarized in Table 2

\section{Race}

For Asian population, the pooled sensitivity, specificity, PLR, NLR, DOR and AUC were $0.81,0.85,5.4,0.22,25$ and 0.90 respectively. For Caucasian, they were $0.79,0.87,6.0,0.24,25$ and 0.89 respectively. For mixed population, they were $0.73,0.89,6.4,0.30,21$ and 0.90 respectively (Table 2 ). Subgroup analysis according to race suggested the diagnostic accuracy of sputum miRNA in NSCLC was excellent in all races.

\section{miRNA profiling}

The pooled analysis suggested combined miRNA may yield higher diagnostic accuracy in distinguish NSCLC. The pooled sensitivity, specificity, PLR, NLR, DOR and AUC were 0.76 vs $0.74,0.88$ vs $0.74,6.4$ vs $2.8,0.28$ vs $0.36,23$ vs 8 and 0.90 vs 0.80 respectively for multiple miRNA vs single miRNA (Table 2 , Figure $4 \mathrm{~A}$ and $4 \mathrm{~B}$, and Figure $5 \mathrm{~A}$ and $5 \mathrm{~B})$.

\section{Source of control}

According the source of control, control subjects could be classified as healthy control, cancer-free control and BPD. Studies with healthy control had a pooled sensitivity of 0.73 , specificity of 0.91 , PLR of 8.5 , NLR of 0.29 , DOR of 29 and AUC of 0.77 . Studies with cancer-free controls had a pooled sensitivity of 0.76 , specificity of 0.86 , PLR of 5.5 , NLR of 0.28 , DOR of 19 and AUC of 0.88 . Studies with BPD controls showed a pooled sensitivity of 0.82 , specificity of 0.86 , PLR 
of 5.7, NLR of 0.22 , DOR of 26 and AUC of 0.91 (Table 2). All these subgroups showed satisfied diagnostic accuracy, suggesting sputum miRNA could not only be a tool for lung cancer screening but also be a tool for differential diagnosis.

\section{Stage}

Firstly, according to percentage of early stage disease, we divided studies as $\mathrm{I} / \mathrm{Il} \geq 0.6$ and $\mathrm{I} / \mathrm{II} \otimes 0.6$ subgroups. Both group showed satisfied diagnostic efficacy, with pooled sensitivity of 0.76 and 0.79 , specificity of 0.88 and 0.85 , PLR of 6.1 and 5.3, NLR of 0.27 and 0.25 , DOR of 23 and 21 , AUC of 0.90 and 0.87 for $\mathrm{I} / \mathrm{II} \geq 0.6$ and $\mathrm{I} / \mathrm{II} 0.6$ subgroup respectively(Table 2 ).

We also extracted studies only focus on stage I and/or II disease for analysis. For stage I and II disease, the pooled sensitivity, specificity, PLR, NLR, DOR and AUC were $0.76,0.88,6.5,0.27,23$ and 0.90 , respectively. For only stage I disease, the pooled sensitivity, specificity, PLR, NLR, DOR and AUC were $0.75,0.88,6.5$, $0.28,23$ and 0.90 , respectively (Table 2, Figure $4 \mathrm{C}$ and $4 \mathrm{D}$ and Figure $5 \mathrm{C}$ and $5 \mathrm{D}$ ). This suggested sputum miRNA could serve as an efficacy tool in early lung cancer screen.

\section{Histology, sample size and publication year}

According to the percentage of adenocarcinoma in overall NSCLC, 0.5 was selected as a cut-off to divided studies as $A D \geq 0.5$ and $A D<0.5$. Both studies showed satisfied diagnostic accuracy. The similar results were found in the subgroup analyses according to sample size and publication year (Table 2).

\section{Meta-regression analyses and publication bias}

Potential sources of inter-study heterogeneity were explored by meta-regression analyses. The analyses suggested race $(P<0.01)$, miRNA profiling $(P<0.01)$ and source of control $(\mathrm{P}<0.01)$ might be the potential sources of inter-study heterogeneity. The effect of samle size, publication year, age, male ratio and smoking on heterogeneity was not significant (Figure 6A). Deeks'funnel plot asymmetry test was applied to detect publication bias. No publication bias was detected in both overall (Figure 6B) and subgroup analyses (Table 2).

\section{Potential useful sputum miRNAs identified from literature}

We sorted the miRNAs reported by at least two studies that could serve as potential biomarkers. In upregulated miRNAs, 11 studies reported miR-210, $11,20-23,25-$ $28,31,32$ eight studies reported miR-21 ${ }^{11,13,19,22,24,25,27,32}$ and six studies reported miR-31. ${ }^{11,21-23,32,37}$ miR-205, ${ }^{11,22,26}$ miR-182, ${ }^{11,19,22}$ miR-200b ${ }^{11,19,22}$ and miR$155^{11,24,26}$ had been reported by three studies. Only miR-372 ${ }^{11,28}$ had been reported by two studies. In downregulated studies, miR-126-3p had been reported by five studies, ${ }^{11,19,22,26,31}$ miR-486 had been reported by three studies ${ }^{11,19,22}$ and miR-145 had been reported by two studies. ${ }^{19,31}$ We also found some conflicting result. Two studies reported miR-375 was upregulated, ${ }^{11,19}$ but another two studies reported it was downregulated. ${ }^{22,31}$ miR-708 was upregulated in two studies ${ }^{11,26}$ and downregulated in one studies. ${ }^{22}$ Further studies should verify these conflicting results(Table 3$)$.

\section{Discussion}

The current studies comprehensively investigated the diagnostic accuracy of sputum miRNAs in NSCLC by sorting current evidence. We found sputum miRNA showed satisfied diagnostic accuracy with a pooled sensitivity of 0.77 and specificity of 0.87 , with corresponding PLR 5.9 and NLR 0.26 . The pooled DOR was 23 and the AUC was 0.89 . Even in various subgroup analyses, the diagnostic accuracy was still very high, suggesting sputum miRNAs might be potential biomarker to distinguish lung cancers from controls.

Previous studies investigated the diagnostic role of circulating miRNAs on lung cancer by meta-analysis ${ }^{33-36}$. According to their report, the pooled sensitivity ranged from 0.76 to 0.83 , specificity ranged from 0.77 to 0.84 , AUC ranged from 0.83 to 0.90 . Our study showed sputum miRNAs have an equivalent diagnostic accuracy when compared with circulating miRNAs. However, sputum was more noninvasive than blood. As a result, sputum miRNAs might serve as more noninvasive and efficacy biomarkers for lung cancer diagnosis.

Previous meta-analysis by Liao et al. published in 2014 had investigated the diagnostic role of sputum miRNAs in lung cancer. ${ }^{37}$ Only 8 studies with 514 lung cancer patients and 491 controls were included in their analyses. They found the pooled sensitivity, specificity, PLR, NLR, DOR and AUC of sputum miRNAs were $0.70,0.89,5.6,0.35,17.5$ and 0.83 , respectively. Our analyses yielded higher diagnostic accuracy when compared with the previous study. This may because our analysis included more studies and more samples than previous work. After 2014, 8 studies were published. In our work, we included 16 articles consisted of 1,212 patients with lung cancer and 1,235 controls. Our sample size was extremely larger than previous study; as a result, our result was more robust and reliable. Also, our analysis was more comprehensively and presented more detailed and useful information. We conducted subgroup analyses by race, miRNA profiling, the source of control, histology type, sample size, publication year and stage.

In subgroup analysis by the source of control, we also demonstrated sputum miRNA could not only screen lung cancer from healthy population, but also distinguish lung cancer from cancer-free/BPD patients. Lung cancer screen in early stage was very important because it could significantly improve the prognosis of this lethal disease. As a result, we conducted subgroup analysis by stage. We found both $\mathrm{I} / \mathrm{II} \geq 0.6(0.90)$ and $\mathrm{I} / \mathrm{II} \mathbf{\mathrm { I }} 0.6$ ( 0.87$)$ subgroup showed good diagnostic performance. We also extract studies only investigated stage I/II and stage I disease. We found sputum miRNA could distinguished stage I/II and stage I NSCLC from controls correctly. This suggested sputum miRNAs could serve as useful biomarkers for NSCLC screen. Other subgroups such as histology type, sample size and publication year also showed satisfied diagnostic accuracy, suggesting sputum miRNA was efficacy and reliable in lung cancer diagnosis. 
Although the diagnostic performance of sputum miRNA was excellent, but the certain miRNAs applied in individual studies were not uniform. These may limited the application of sputum miRNAs. We sorted certain miRNAs used in each study, and we found miR-210, miR-21, miR-31 and miR-126-3p was most frequently applied miRNAs. Our studies supplied some evidence that these miRNA might serve as useful potential sputum biomarkers. Future studies should further verify these miRNAs and applied as a high efficacy panel to improve the diagnostic accuracy. Another problem was the cutoff value was various among each studies. Established standard reference for these useful sputum miRNAs was necessary for their further utility. Also, combining sputum miRNAs with CT screening, sputum cytology and serum tumor protein markers, such as cytokeratin 19 fragment (CYFRA21-1), squamous cell carcinoma antigen (SCC) and carcinoembryonic antigen (CEA) could yield more satisfied diagnostic performance.

High heterogeneity was existed in our analysis. Meta-regression analysis was done to explore the potential sources of heterogeneity. We found race, miRNA profling and the source of control might be the major cause of heterogeneity. Also, lacking uniform cutoff values and certain miRNAs in each study was the one of the major source of heterogeneity. This should be acknowledged and interpreted with caution.

\section{Conclusion}

The present studies supported sputum miRNAs was a useful noninvasive biomarkers for NSCLC diagnosis. Combinations of miRNAs may yield satisfied diagnostic accuracy. miR-210, miR-21, miR-31 and miR-126-3p was most frequently applied miRNAs in current evidence and might serve as useful sputum miRNAs in the diagnosis of NSCLC. However, the clinical application of miRNA profiling for NSCLC detection still needs further validation by future studies.

\section{Declarations}

\section{Acknowledgements}

Not applicable.

\section{Authors' contributions}

Zaoxiu Hu put forward the idea and designed the research; All authors contributed to literature searching, data extraction and analysis; Zaoxiu Hu wrote the manuscript; Yunchao Huang and Yonghe Zhao revised the manuscript; The authors approved the final version of the manuscript.

\section{Funding}

This research is supported by Scientific research fund project of Yunnan Provincial Department of Education, China (grant number 2019J1282), and National Key Research and Development Program of China (grant number 2017YFC0907902).

\section{Availability of data and materials}

The datasets generated and analyzed during the current study are available from the corresponding author on reasonable request.

\section{Ethics approval and consent to participate}

Not applicable.

\section{Consent for publication}

Not applicable.

\section{Competing interests}

The authors declare that they have no competing interests.

\section{References}

1. Torre LA, Bray F, Siegel RL, Ferlay J, Lortet-Tieulent J, Jemal A. Global cancer statistics, 2012. CA Cancer J Clin. 2015;65(2):87-108.

2. Chen W, Zheng R, Baade PD, et al. Cancer statistics in China, 2015. CA Cancer J Clin. 2016;66(2):115-32.

3. Siegel RL, Miller KD, Jemal A. Cancer Statistics. 2017. CA Cancer J Clin. 2017;67(1):7-30.

4. Herbst RS, Heymach JV, Lippman SM. Lung cancer. N Engl J Med. 2008;359(13):1367-80.

5. Detterbeck FC, Chansky K, Groome P, et al. The IASLC Lung Cancer Staging Project: Methodology and Validation Used in the Development of Proposals for Revision of the Stage Classification of NSCLC in the Forthcoming (Eighth) Edition of the TNM Classification of Lung Cancer. J Thorac Oncol. 2016;11(9):1433-46.

6. National Lung Screening Trial. Research T, Aberle DR, Adams AM, et al. Reduced lung-cancer mortality with low-dose computed tomographic screening. N Engl J Med 2011;365(5):395-409.

7. van der Aalst CM, Ten Haaf K, de Koning HJ. Lung cancer screening: latest developments and unanswered questions. Lancet Respir Med. 2016;4(9):74961.

8. Zamay TN, Zamay GS, Kolovskaya OS, et al. Current and Prospective Protein Biomarkers of Lung Cancer. Cancers (Basel). 2017;9(11). 
9. Saccomanno G, Saunders RP, Archer VE, Auerbach O, Kuschner M, Beckler PA. Cancer of the lung: the cytology of sputum prior to the development of carcinoma. Acta Cytol. 1965;9(6):413-23.

10. Hubers AJ, Prinsen CF, Sozzi G, Witte BI, Thunnissen E. Molecular sputum analysis for the diagnosis of lung cancer. Br J Cancer. 2013;109(3):530-7.

11. Xing L, Su J, Guarnera MA, et al. Sputum microRNA biomarkers for identifying lung cancer in indeterminate solitary pulmonary nodules. Clin Cancer Res. 2015;21(2):484-9.

12. Ruan K, Fang X, Ouyang G. MicroRNAs: novel regulators in the hallmarks of human cancer. Cancer Lett. 2009;285(2):116-26.

13. Xie Y, Todd NW, Liu Z, et al. Altered miRNA expression in sputum for diagnosis of non-small cell lung cancer. Lung Cancer. 2010;67(2):170-6.

14. Whiting PF, Rutjes AW, Westwood ME, et al. QUADAS-2: a revised tool for the quality assessment of diagnostic accuracy studies. Ann Intern Med. 2011;155(8):529-36.

15. Deeks JJ. Systematic reviews in health care: Systematic reviews of evaluations of diagnostic and screening tests. BMJ. 2001;323(7305):157-62.

16. Glas AS, Lijmer JG, Prins MH, Bonsel GJ, Bossuyt PM. The diagnostic odds ratio: a single indicator of test performance. J Clin Epidemiol. 2003;56(11):1129-35.

17. Higgins JP, Thompson SG, Deeks JJ, Altman DG. Measuring inconsistency in meta-analyses. BMJ. 2003;327(7414):557-60.

18. Deeks JJ, Macaskill P, Irwig L. The performance of tests of publication bias and other sample size effects in systematic reviews of diagnostic test accuracy was assessed. J Clin Epidemiol. 2005;58(9):882-93.

19. Yu L, Todd NW, Xing L, et al. Early detection of lung adenocarcinoma in sputum by a panel of microRNA markers. Int J Cancer. 2010;127(12):2870-8.

20. Roa WH, Kim JO, Razzak R, et al. Sputum microRNA profiling: a novel approach for the early detection of non-small cell lung cancer. Clin Invest Med. 2012;35(5):E271.

21. Anjuman N, Li N, Guarnera M, Stass SA, Jiang F. Evaluation of lung flute in sputum samples for molecular analysis of lung cancer. Clin Transl Med. 2013;2(1):15.

22. Shen J, Liao J, Guarnera MA, et al. Analysis of MicroRNAs in sputum to improve computed tomography for lung cancer diagnosis. J Thorac Oncol. 2014;9(1):33-40.

23. Li N, Ma J, Guarnera MA, Fang H, Cai L, Jiang F. Digital PCR quantification of miRNAs in sputum for diagnosis of lung cancer. J Cancer Res Clin Oncol. 2014;140(1):145-50.

24. Yang XQ, Zhang YH, Sun B, et al. Diagnostic value of the detection of MicroRNAs in sputum of patients with non-small cell lung cancer. J Clin Pulm Med. 2013;18(2):226-8.

25. Kim JO, Gazala S, Razzak R, et al. Non-small cell lung cancer detection using microRNA expression profiling of bronchoalveolar lavage fluid and sputum. Anticancer Res. 2015;35(4):1873-80.

26. Xing L, Todd NW, Yu L, Fang H, Jiang F. Early detection of squamous cell lung cancer in sputum by a panel of microRNA markers. Mod Pathol. 2010;23(8):1157-64.

27. Su Y, Fang H, Jiang F. Integrating DNA methylation and microRNA biomarkers in sputum for lung cancer detection. Clin Epigenetics. 2016;8:109.

28. Razzak R, Bedard EL, Kim JO, et al. MicroRNA expression profiling of sputum for the detection of early and locally advanced non-small-cell lung cancer: a prospective case-control study. Curr Oncol. 2016;23(2):e86-94.

29. Sheervalilou R. Khamaneh, et al. Using miR-10b, miR-1 and miR-30a expression profiles of bronchoalveolar lavage and sputum for early detection of nonsmall cell lung cancer. Biomedicine pharmacotherapy =: Biomedecine pharmacotherapie. 2017;88:1173-82.

30. Bagheri A, Khorram Khorshid HR, Mowla SJ, et al. Altered miR-223 Expression in Sputum for Diagnosis of Non-Small Cell Lung Cancer. Avicenna J Med Biotechnol. 2017;9(4):189-95.

31. Bagheri A, Khorshid HRK, Tavallaie M, et al. A panel of noncoding RNAs in non-small-cell lung cancer. J Cell Biochem. 2018.

32. Su J, Leng Q, Lin Y, et al. Integrating Circulating Immunological and Sputum Biomarkers for the Early Detection of Lung Cancer. Biomark Cancer. 2018;10:1179299 × 18759297.

33. Yang Y, Hu Z, Zhou Y, et al. The clinical use of circulating microRNAs as non-invasive diagnostic biomarkers for lung cancers. Oncotarget. 2017;8(52):90197-214.

34. Chen L, Jin H. MicroRNAs as novel biomarkers in the diagnosis of non-small cell lung cancer: a meta-analysis based on 20 studies. Tumour Biol. 2014;35(9):9119-29.

35. Guo Z, Zhao C, Wang Z. MicroRNAs as ideal biomarkers for the diagnosis of lung cancer. Tumour Biol. 2014;35(10):10395-407.

36. Wang H, Wu S, Zhao L, Zhao J, Liu J, Wang Z. Clinical use of microRNAs as potential non-invasive biomarkers for detecting non-small cell lung cancer: a meta-analysis. Respirology. 2015;20(1):56-65.

37. Liao QB, Guo JQ, Zheng XY, et al. Test performance of sputum microRNAs for lung cancer: a meta-analysis. Genet Test Mol Biomarkers. 2014;18(8):5627.

\section{Tables}

Table 1. Characteristics of included studies. 


\begin{tabular}{|c|c|c|c|c|c|c|c|c|c|}
\hline Study,year & Country (ethnicity) & $\begin{array}{l}\text { No. of } \\
\text { cases/control }\end{array}$ & $\begin{array}{l}\text { Mean age } \\
\text { (case/control) }\end{array}$ & $\begin{array}{l}\text { Male ratio } \\
\text { (case/control) }\end{array}$ & $\begin{array}{l}\text { Smoking } \\
\text { status (pack- } \\
\text { years) } \\
\text { (case/control) }\end{array}$ & $\begin{array}{l}A D \\
\text { ratio }\end{array}$ & $\begin{array}{l}\text { Stage(I/II } \\
\text { ratio) }\end{array}$ & $\begin{array}{l}\text { Source } \\
\text { of } \\
\text { controls }\end{array}$ & miRNA \\
\hline Xie Y,2010 & USA(Caucasian) & $23 / 17$ & $68.1 / 45.5$ & $0.78 / 0.71$ & $40.5 / 16.2$ & 0.56 & $\mathrm{I}-\mathrm{IV}(0.35)$ & $\mathrm{CF}$ & miR-21 \\
\hline $\begin{array}{l}\text { Yu L,2010 }{ }^{19} \text {, stage I } \\
\text { cohort }\end{array}$ & USA(mixed) & $36 / 36$ & $68.2 / 66.7$ & $0.56 / 0.56$ & $28.6 / 28.8$ & 1.00 & $\mathrm{I}(1.00)$ & $\mathrm{HC}$ & $\begin{array}{l}\text { miR-48! } \\
\text { and 37! }\end{array}$ \\
\hline Independent cohort & USA(mixed) & $64 / 58$ & $67 / 65$ & $0.58 / 0.54$ & $30.9 / 27.7$ & 0.52 & I-IV(0.48) & $\mathrm{HC}$ & miR-48। \\
\hline Roa,2012 20 & Canada(Caucasian) & $24 / 6$ & $69 / 54$ & $0.67 / 0.80$ & $92.0 / 40.0$ & 0.71 & $|-| \mid(1.00)$ & $\mathrm{CF}$ & miR-21, \\
\hline Anjuman,201321 & USA(mixed) & $39 / 42$ & $65.6 / 62.3$ & $0.59 / 0.60$ & $48.5 / 46.7$ & 0.54 & $\mathrm{I}(1.00)$ & $\mathrm{CF}$ & miR-48। \\
\hline $\begin{array}{l}\text { Shen J,201422, } \\
\text { training Set }\end{array}$ & USA(mixed) & $66 / 68$ & $64 / 67$ & $0.56 / 0.62$ & $53.0 / 49.0$ & 0.41 & $\mathrm{I}-\mathrm{IV}(0.66)$ & CF & $\begin{array}{l}\text { miR- } \\
21,126 ; \\
5 p, 708 ;\end{array}$ \\
\hline Testing Set & USA(mixed) & $64 / 73$ & $66 / 64$ & $0.64 / 0.66$ & $55 / 50$ & 0.47 & I-IV(0.66) & $\mathrm{CF}$ & miR-21। \\
\hline Li N, $2013^{23}$ & USA(mixed) & $35 / 40$ & $68.9 / 65.7$ & $0.63 / 0.65$ & $48.4 / 20.8$ & 0.54 & $\mathrm{I}(1.00)$ & $\mathrm{CF}$ & miR-21। \\
\hline Yang $X, 2013^{24}$ & China(Asian) & $24 / 24$ & $60.5 / 57.8$ & $0.67 / 0.71$ & $40.0 / 15.0$ & 0.33 & $\mathrm{I}-\mathrm{IV}(0.38)$ & BPD & miR-21, \\
\hline Kim, $2015^{25}$ & Canada(Caucasian) & $21 / 10$ & $70 / 59$ & $0.81 / 0.80$ & $44.0 / 40.0$ & 0.62 & $|-| \mid(1.00)$ & $\mathrm{CF} / \mathrm{HC}$ & miR-21, \\
\hline $\begin{array}{l}\text { Xing } L, 2010^{26} \\
\text { case-control cohort }\end{array}$ & USA(mixed) & $48 / 48$ & $67.5 / 65.9$ & $0.58 / 0.58$ & $30.6 / 29.3$ & 0 & $\mathrm{I}(1.00)$ & $\mathrm{HC}$ & $\begin{array}{l}\operatorname{miR}-20 ! \\
429\end{array}$ \\
\hline Independent cohort & USA(mixed) & $67 / 55$ & $68 / 65$ & $0.69 / 0.64$ & $31.1 / 26.8$ & 0 & $\mathrm{I}-\mathrm{IV}(0.45)$ & $\mathrm{HC}$ & $\begin{array}{l}\operatorname{miR}-20 ! \\
429\end{array}$ \\
\hline $\begin{array}{l}\text { Xing } \\
\text { L,2015 }{ }^{11} \text {,Training } \\
\text { set }\end{array}$ & USA(mixed) & $60 / 62$ & $67.3 / 66.4$ & $0.63 / 0.63$ & $37.3 / 32.6$ & 0.45 & $|-| \mid(1.00)$ & $\begin{array}{l}\text { Beingin } \\
\text { SPN }\end{array}$ & miR-21, \\
\hline Internal testing set & USA(mixed) & $67 / 69$ & $66.4 / 64.9$ & $0.64 / 0.67$ & $36.9 / 34.6$ & 0.45 & $\mathrm{H}-\mathrm{I}(1.00)$ & $\begin{array}{l}\text { Beingin } \\
\text { SPN }\end{array}$ & miR-21, \\
\hline External testing set & USA(mixed) & $76 / 79$ & $68.7 / 67.9$ & $0.64 / 0.67$ & $39.3 / 32.7$ & 0.45 & $|-| \mid(1.00)$ & $\begin{array}{l}\text { Beingin } \\
\text { SPN }\end{array}$ & miR-21, \\
\hline $\begin{array}{l}\text { Su Y,2016 } \\
\text { training set }\end{array}$ & China(Asian) & $117 / 174$ & $66.5 / 65.4$ & $0.80 / 0.79$ & $45.8 / 44.7$ & 0.54 & $\mathrm{I}(1.00)$ & $\begin{array}{l}\text { Beingin } \\
\text { SPN }\end{array}$ & miR-21, \\
\hline Testing set & China(Asian) & $144 / 171$ & $66.3 / 65.2$ & $0.79 / 0.79$ & $44.4 / 43.3$ & 0.54 & $\mathrm{I}(1.00)$ & $\begin{array}{l}\text { Bingin } \\
\text { SPN }\end{array}$ & miR-21, \\
\hline Razzak,2016 28 & Canada(Caucasian) & $43 / 10$ & $70.0 / 58.0$ & $0.62 / 0.80$ & $40.1 / 41.7$ & 0.54 & $\mathrm{I}-\mathrm{IV}(0.49)$ & $\mathrm{CF}$ & miR-21, \\
\hline Sheervalilou, $2017^{29}$ & Iran(Caucasian) & $30 / 30$ & NR & $0.60 / 0.50$ & $50.0 / 50.0$ & 0.43 & I-III(0.73) & CF & miR-10l \\
\hline Bagheri, $2017^{30}$ & Iran(Caucasian) & $17 / 17$ & NR & $0.88 / 0.88$ & NR & 0.65 & $\mathrm{I}-\mathrm{IV}(0.29)$ & CF & miR-22: \\
\hline Bagheri,2018 31 & Iran(Caucasian) & $30 / 30$ & $62.9 / 60.5$ & $0.87 / 0.87$ & 26.7/13.3 & 0.80 & $\mathrm{I}-\mathrm{IV}(0.50)$ & $\mathrm{CF}$ & $\begin{array}{l}\text { miR- } \\
145,12 \epsilon \\
\text { and } 37 !\end{array}$ \\
\hline $\begin{array}{l}\text { Su J,2018 } \\
\text { discovery cohort }\end{array}$ & USA(mixed) & $68 / 66$ & $64.5 / 64.7$ & $0.59 / 0.58$ & $34.6 / 33.3$ & 0.54 & $\mathrm{I}-\mathrm{IV}(0.62)$ & $\mathrm{CF}$ & miR-31, \\
\hline Validation cohort & USA(mixed) & $49 / 50$ & $65.2 / 64.7$ & $0.61 / 0.60$ & $35.5 / 35.2$ & 0.53 & $\mathrm{I}-\mathrm{IV}(0.61)$ & $\mathrm{CF}$ & miR-31, \\
\hline
\end{tabular}

Note: $\mathrm{AD}$, adenocarcinoma; $\mathrm{NR}$, not report; $\mathrm{CF}$, cancer-free; $\mathrm{HC}$, healthy control; $\mathrm{BPD}$, benign pulmonary disease; SPN, solitary pulmonary nodule Table 2. the main results of meta-analysis. 


\begin{tabular}{|c|c|c|c|c|c|c|c|}
\hline Analysis & $\begin{array}{l}\text { No. of } \\
\text { studies }\end{array}$ & SEN $(95 \% \mathrm{Cl})$ & SPE $(95 \% \mathrm{Cl})$ & PLR $(95 \% \mathrm{Cl})$ & $\operatorname{NLR}(95 \% \mathrm{Cl})$ & $\begin{array}{l}\text { DOR } \\
(95 \% \mathrm{Cl})\end{array}$ & AUC $(95$ \\
\hline Overall & 30 & $0.77(0.73,0.81),\left.\right|^{2}=54.0 \%, p<0.001$ & $0.87(0.83,0.90), I^{2}=70.2 \%, p<0.001$ & $5.9(4.7,7.4)$ & $0.26(0.22,0.30)$ & $23(18,29)$ & $0.89(0 . \varepsilon$ \\
\hline \multicolumn{8}{|l|}{$\begin{array}{l}\text { Subgroup } \\
\text { 1: race }\end{array}$} \\
\hline Asian & 5 & $0.81(0.77,0.85), I^{2}=0.0 \%, p=0.86$ & $0.85(0.81,0.88), I^{2}=0.0 \%, p=0.71$ & $5.4(4.3,6.8)$ & $0.22(0.17,0.28)$ & $25(17,36)$ & $0.90(0 . \varepsilon$ \\
\hline Caucasian & 14 & $0.79(0.70,0.86), I^{2}=62.8 \%, p<0.001$ & $0.87(0.76,0.93), I^{2}=80.3 \%, p<0.001$ & $6.0(3.3,10.7)$ & $0.24(0.17,0.33)$ & $25(13,46)$ & $0.89(0 . \varepsilon$ \\
\hline Mixed & 11 & $0.73(0.68,0.77), I^{2}=43.3 \%, p=0.06$ & $0.89(0.86,0.91), I^{2}=10.1 \%, p=0.35$ & $6.4(5.1,8)$ & $0.30(0.26,0.36)$ & $21(15,29)$ & $0.90(0 . \varepsilon$ \\
\hline \multicolumn{8}{|c|}{$\begin{array}{l}\text { Subgroup2: miRNA } \\
\text { profiling }\end{array}$} \\
\hline $\begin{array}{l}\text { Single } \\
\text { miRNA }\end{array}$ & 38 & $0.74(0.67,0.79),\left.\right|^{2}=72.2 \%, p<0.001$ & $0.74(0.68,0.78), I^{2}=77.8 \%, p<0.001$ & $2.8(2.4,3.3)$ & $0.36(0.30,0.43)$ & $8(6,10)$ & $0.80(0.7$ \\
\hline $\begin{array}{l}\text { Multiple } \\
\text { miRNA }\end{array}$ & 11 & $0.76(0.72,0.79), l^{2}=47.6 \%, p=0.01$ & $0.88(0.86,0.90), l^{2}=0.0 \%, p=0.74$ & $6.4(5.4,7.5)$ & $0.28(0.24,0.32)$ & $23(18,29)$ & $0.90(0 . \varepsilon$ \\
\hline \multicolumn{8}{|c|}{ Subgroup3: source of control } \\
\hline $\mathrm{HC}$ & 4 & $0.73(0.67,0.79), I^{2}=0.0 \%, p=0.71$ & $0.91(0.83,0.96), l^{2}=71.6 \%, p=0.01$ & $8.5(4.0,17.9)$ & $0.29(0.23,0.38)$ & $29(12,70)$ & $0.77(0.7$ \\
\hline $\begin{array}{l}\text { Cancer- } \\
\text { free } \\
\text { control }\end{array}$ & 18 & $0.76(0.68,0.82), l^{2}=61.0 \%, p<0.001$ & $0.86(0.79,0.91), I^{2}=78.8 \%, p<0.001$ & $5.5(3.8,8.0)$ & $0.28(0.22,0.36)$ & $19(13,29)$ & $0.88(0 . \varepsilon$ \\
\hline BPD & 8 & $0.82(0.78,0.85), I^{2}=0.0 \%, p=0.98$ & $0.86(0.83,0.88), I^{2}=0.0 \%, p=0.89$ & $5.7(4.7,6.9)$ & $0.22(0.18,0.26)$ & $26(19,36)$ & $0.91(0 . \varepsilon$ \\
\hline \multicolumn{8}{|c|}{$\begin{array}{l}\text { Subgroup4: histology } \\
\text { type }\end{array}$} \\
\hline$A D>50 \%$ & 16 & $0.79(0.72,0.84), I^{2}=60.2 \%, p<0.001$ & $0.86(0.78,0.91), I^{2}=79.57 \%, p<0.001$ & $5.5(3.7,8.2)$ & $0.25(0.20,0.32)$ & $22(15,33)$ & $0.88(0 . \varepsilon$ \\
\hline$A D<50 \%$ & 14 & $0.76(0.72,0.80), l^{2}=23.1 \%, p=0.19$ & $0.88(0.85,0.90), I^{2}=0.0 \%, p=0.46$ & $6.5(5.3,8.0)$ & $0.27(0.23,0.31)$ & $24(18,32)$ & $0.91(0 . \varepsilon$ \\
\hline \multicolumn{8}{|c|}{$\begin{array}{l}\text { Subgroup5: sample } \\
\text { size }\end{array}$} \\
\hline$>100$ & 10 & $0.77(0.72,0.81), I^{2}=56.2 \%, p=0.01$ & $0.87(0.85,0.89), l^{2}=0.0 \%, p=0.62$ & $6.0(5.0,7.2)$ & $0.27(0.22,0.32)$ & $22(17,30)$ & $0.90(0 . \varepsilon$ \\
\hline$<100$ & 20 & $0.77(0.71,0.83),\left.\right|^{2}=54.5 \%, p<0.001$ & $0.87(0.79,0.91), I^{2}=76.8 \%, p<0.001$ & $5.8(3.8,8.6)$ & $0.26(0.21,0.33)$ & $22(14,34)$ & $0.88(0 . \varepsilon$ \\
\hline \multicolumn{8}{|c|}{$\begin{array}{l}\text { Subgroup6:publication } \\
\text { year }\end{array}$} \\
\hline$>2015$ & 17 & $0.81(0.75,0.86),\left.\right|^{2}=57.7 \%, p<0.001$ & $0.86(0.79,0.90), I^{2}=76.7 \%, p<0.001$ & $5.6(4.0,8.0)$ & $0.22(0.17,0.28)$ & $25(19,34)$ & $0.90(0 . \varepsilon$ \\
\hline$<2015$ & 13 & $0.71(0.67,0.75), I^{2}=10.75 \%, p=0.34$ & $0.89(0.85,0.92), I^{2}=37.0 \%, p=0.09$ & $6.3(4.7,8.7)$ & $0.32(0.28,0.37)$ & $20(13,29)$ & $0.77(0.7$ \\
\hline \multicolumn{8}{|c|}{ Subgroup7: stage } \\
\hline $\mathrm{I} / \mathrm{II}>0.6$ & 18 & $0.76(0.72,0.80), I^{2}=52.2 \%, p=0.01$ & $0.88(0.85,0.90), I^{2}=0.0 \%, p=0.91$ & $6.1(5.2,7.2)$ & $0.27(0.23,0.32)$ & $23(17,29)$ & $0.90(0 . \varepsilon$ \\
\hline $\mathrm{I} / \mathrm{I}<0.6$ & 12 & $0.79(0.69,0.86), l^{2}=60.0 \%, p<0.001$ & $0.85(0.72,0.93), I^{2}=83.5 \%, p<0.001$ & $5.3(2.8,9.8)$ & $0.25(0.18,0.35)$ & $21(11,40)$ & $0.87(0 . \varepsilon$ \\
\hline \multicolumn{8}{|c|}{ Subgroup8: stage I/II } \\
\hline $\begin{array}{l}\text { Stage I/II } \\
\text { patients }\end{array}$ & 16 & $0.76(0.72,0.80), l^{2}=23.1 \%, p=0.19$ & $0.88(0.85,0.90), I^{2}=0.0 \%, p=0.46$ & $6.5(5.3,8.0)$ & $0.27(0.23,0.31)$ & $24(18,32)$ & $0.91(0 . \varepsilon$ \\
\hline $\begin{array}{l}\text { Stage I } \\
\text { patients }\end{array}$ & 8 & $0.75(0.69,0.80), l^{2}=40.7 \%, p=0.11$ & $0.88(0.85,0.91), l^{2}=28.8 \%, p=0.20$ & $6.5(4.9,8.6)$ & $0.28(0.22,0.35)$ & $23(16,34)$ & $0.90(0 . \varepsilon$ \\
\hline
\end{tabular}

Note: $C F$, cancer-free; $H C$, healthy control; BPD, benign pulmonary disease; AD, adenocarcinoma; SEN, sensitivity; SPE, specificity; PLR, positive likelihood ratio (PLR); NLR, negative likelihood ratio; DOR, diagnostic odds ratio; AUC, area under the curve.

Table 3.The differentially expressed miRNAs with a consistent direction reported in at least two studies 


\begin{tabular}{|c|c|c|c|c|c|c|}
\hline miRNAs & Accession & Mature sequence & Source & $\begin{array}{l}\text { Direction of } \\
\text { expression }\end{array}$ & $\begin{array}{l}\text { No of } \\
\text { studies } \\
\text { reported }\end{array}$ & Reference \\
\hline \multicolumn{7}{|l|}{ Upregulated } \\
\hline $\begin{array}{l}\text { hsa-miR-210- } \\
5 p\end{array}$ & MIMAT0026475 & AGCCCCUGCCCACCGCACACUG & literature & $\uparrow$ & 11 & $11,20-23,25-28,31,32$ \\
\hline hsa-miR-21-5p & MIMAT0000076 & UAGCUUAUCAGACUGAUGUUGA & literature & $\uparrow$ & 8 & $11,13,19,22,24,25,27,32$ \\
\hline hsa-miR-31-5p & MIMAT0000089 & AGGCAAGAUGCUGGCAUAGCU & microarray & $\uparrow$ & 6 & $11,21-23,32,37$ \\
\hline $\begin{array}{l}\text { hsa-miR-205- } \\
5 p\end{array}$ & MIMAT0000266 & UCCUUCAUUCCACCGGAGUCUG & microarray,literature & $\uparrow$ & 3 & $11,22,26$ \\
\hline $\begin{array}{l}\text { hsa-miR-182- } \\
5 p\end{array}$ & MIMAT0000259 & UUUGGCAAUGGUAGAACUCACACU & literature & $\uparrow$ & 3 & $11,19,22$ \\
\hline $\begin{array}{l}\text { hsa-miR-200b- } \\
3 p\end{array}$ & MIMAT0000318 & UAAUACUGCCUGGUAAUGAUGA & microarray & $\uparrow$ & 3 & $11,19,22$ \\
\hline $\begin{array}{l}\text { hsa-miR-155- } \\
5 p\end{array}$ & MIMAT0000646 & UUAAUGCUAAUCGUGAUAGGGGUU & literature & $\uparrow$ & 3 & $11,24,26$ \\
\hline $\begin{array}{l}\text { hsa-miR-372- } \\
5 p\end{array}$ & MIMAT0026484 & CCUCAAAUGUGGAGCACUAUUCU & microarray & $\uparrow$ & 2 & 11,28 \\
\hline \multicolumn{7}{|l|}{ Downregulated } \\
\hline $\begin{array}{l}\text { hsa-miR-126- } \\
3 p\end{array}$ & MIMAT0000445 & UCGUACCGUGAGUAAUAAUGCG & microarray,literature & $\downarrow$ & 5 & $11,19,22,26,31$ \\
\hline $\begin{array}{l}\text { hsa-miR-486- } \\
5 p\end{array}$ & MIMAT0002177 & UCCUGUACUGAGCUGCCCCGAG & microarray & $\downarrow$ & 3 & $11,19,22$ \\
\hline $\begin{array}{l}\text { hsa-miR-145- } \\
5 p\end{array}$ & MIMAT0000437 & GUCCAGUUUUCCCAGGAAUCCCU & microarray,literature & $\downarrow$ & 2 & 19,31 \\
\hline \multicolumn{7}{|l|}{ Conflicting } \\
\hline \multirow[t]{2}{*}{$\begin{array}{l}\text { hsa-miR-375- } \\
5 p\end{array}$} & MIMAT0037313 & GCGACGAGCCCCUCGCACAAACC & microarray & $\uparrow$ & 2 & 11,19 \\
\hline & & & & $\downarrow$ & 2 & 22,31 \\
\hline \multirow[t]{2}{*}{$\begin{array}{l}\text { hsa-miR-708- } \\
5 p\end{array}$} & MIMAT0004926 & AAGGAGCUUACAAUCUAGCUGGG & microarray & $\downarrow$ & 2 & 11,26 \\
\hline & & & & $\uparrow$ & 1 & 22 \\
\hline
\end{tabular}

\section{Figures}


A

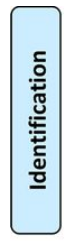

\begin{tabular}{|c|}
\hline $\begin{array}{c}\text { Additional records identified through } \\
\text { other sources } \\
(\mathrm{n}=0)\end{array}$ \\
\hline
\end{tabular}

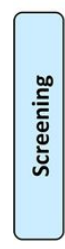

Records after duplicates removed

$(\mathrm{n}=37)$

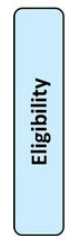

Records identified through database
searching searching
$(\mathrm{n}=\mathbf{2 1 5})$
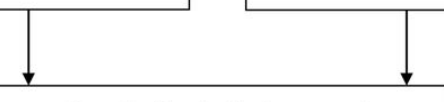

资
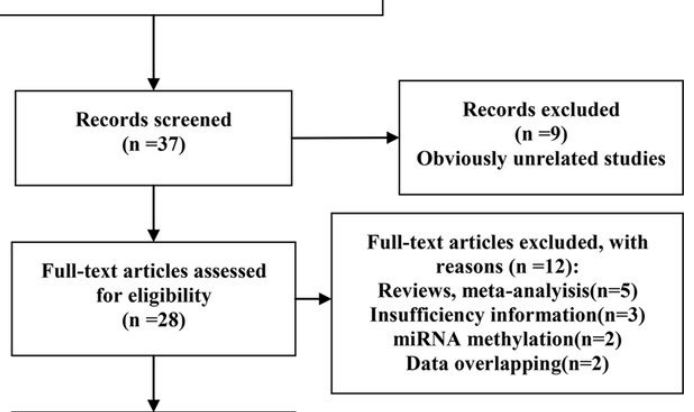

Studies included in

qualitative synthesis

$(n=16)$

롷

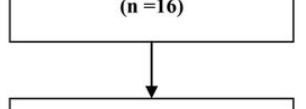

Studies included in quantitative synthesis

(meta-analysis)

$(\mathrm{n}=16)$

B

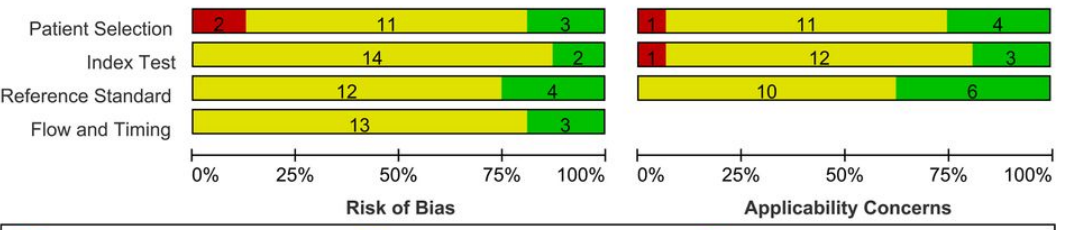

High $\square$ Unclear $\square$ Low

\section{Figure 1}

Flow chart of the study selection process (A) and quality of included studies according to QUADAS-2 guidelines (B). 


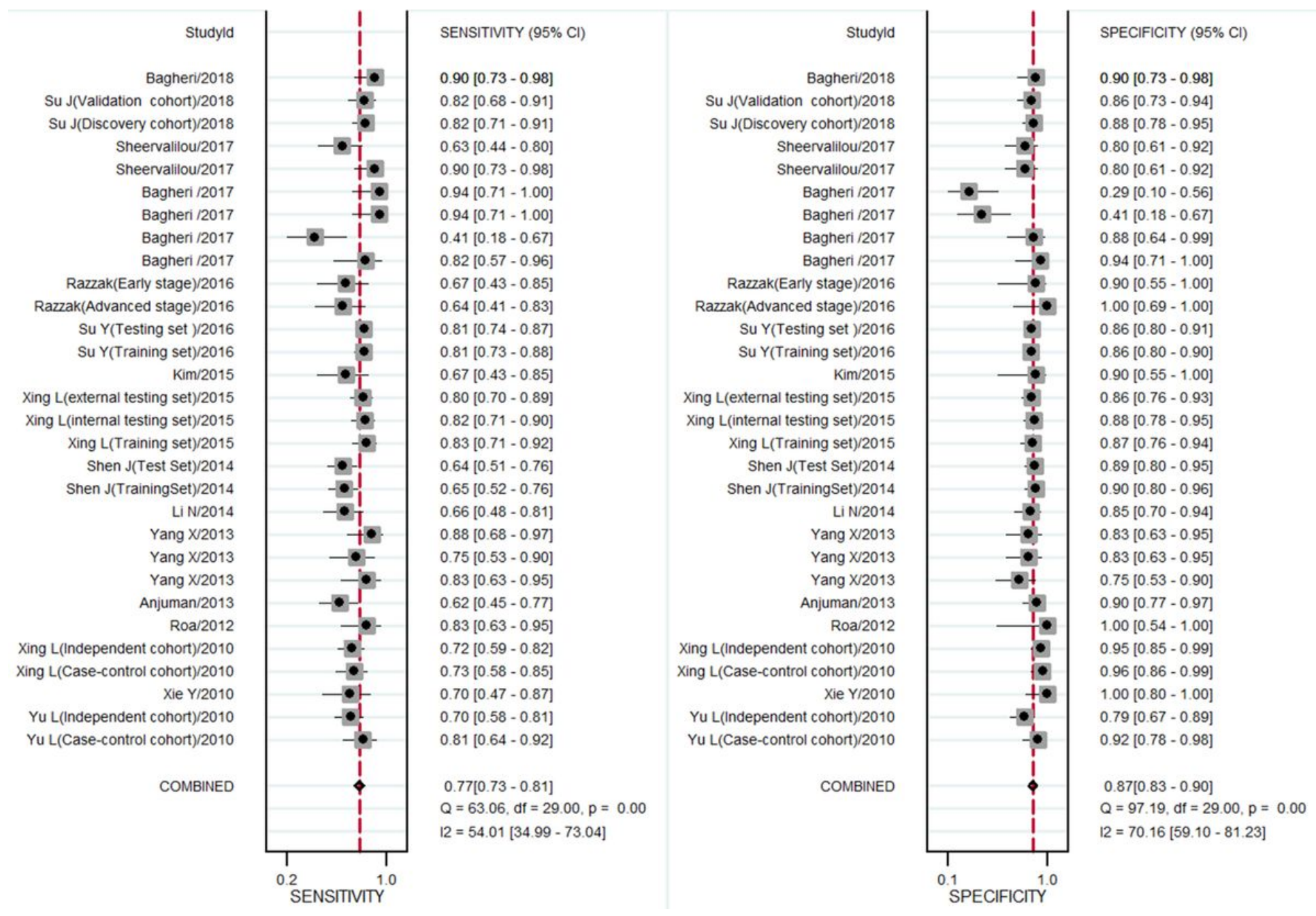

Figure 2

Forest plots of sensitivity and specificity for sputum miRNAs in the diagnosis of NSCLC patients in overall population. 
A

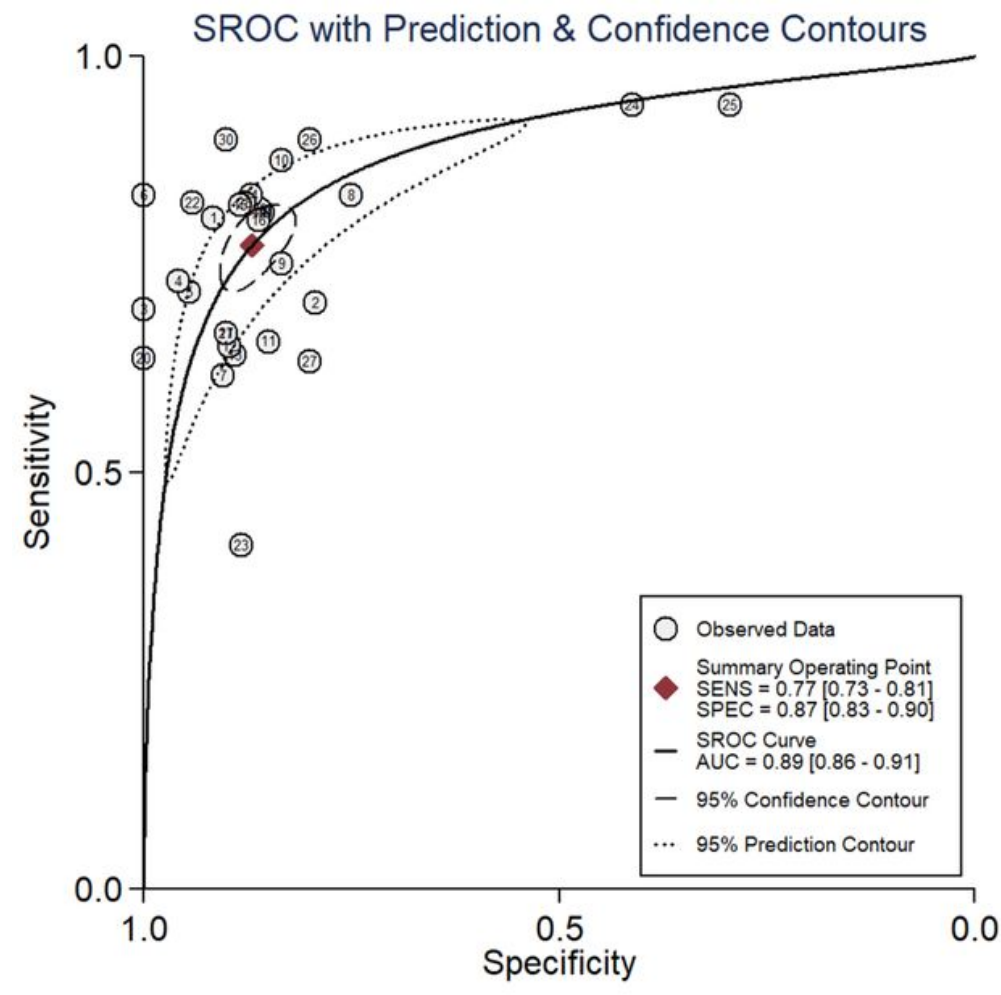

B

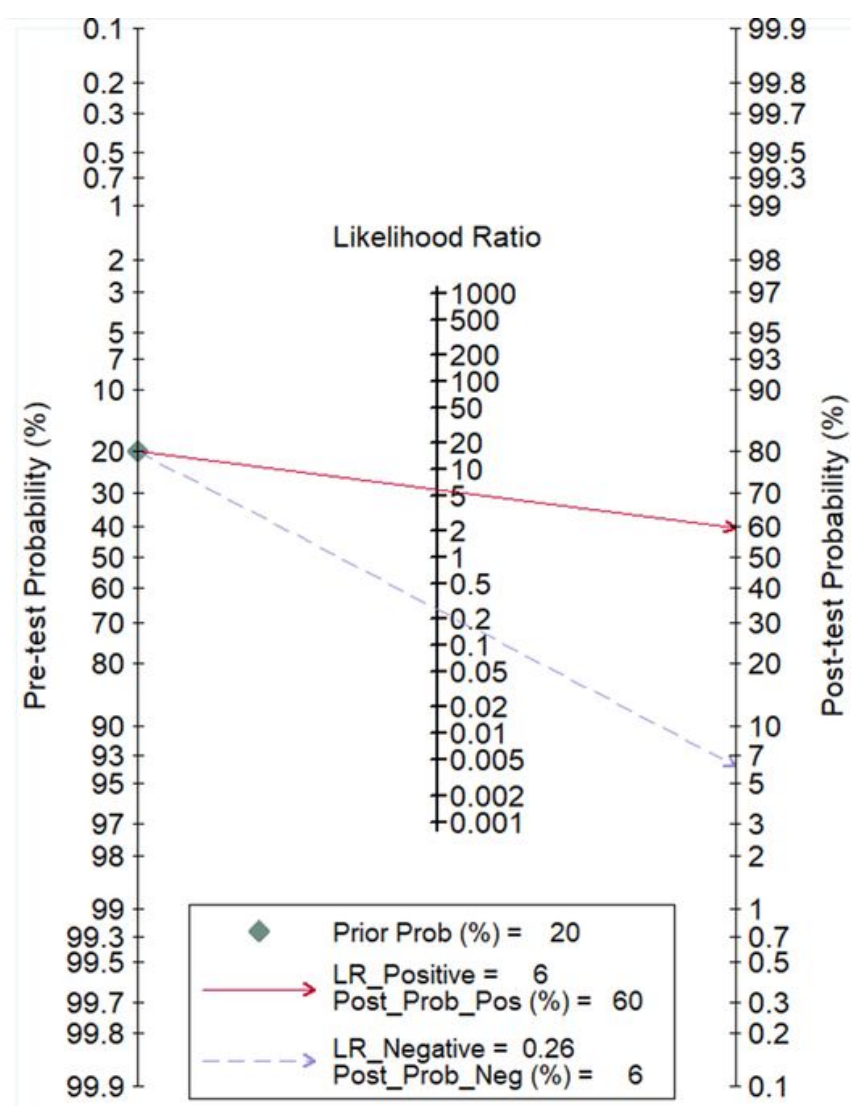

Figure 3

The summary receiver operator characteristic (SROC) curves of sputum miRNA for the diagnosis of NSCLC patients in overall population(A) and Fagan diagram evaluating the positive likelihood ratio (PLR) and negative likelihood ratio (NLR)(B). 

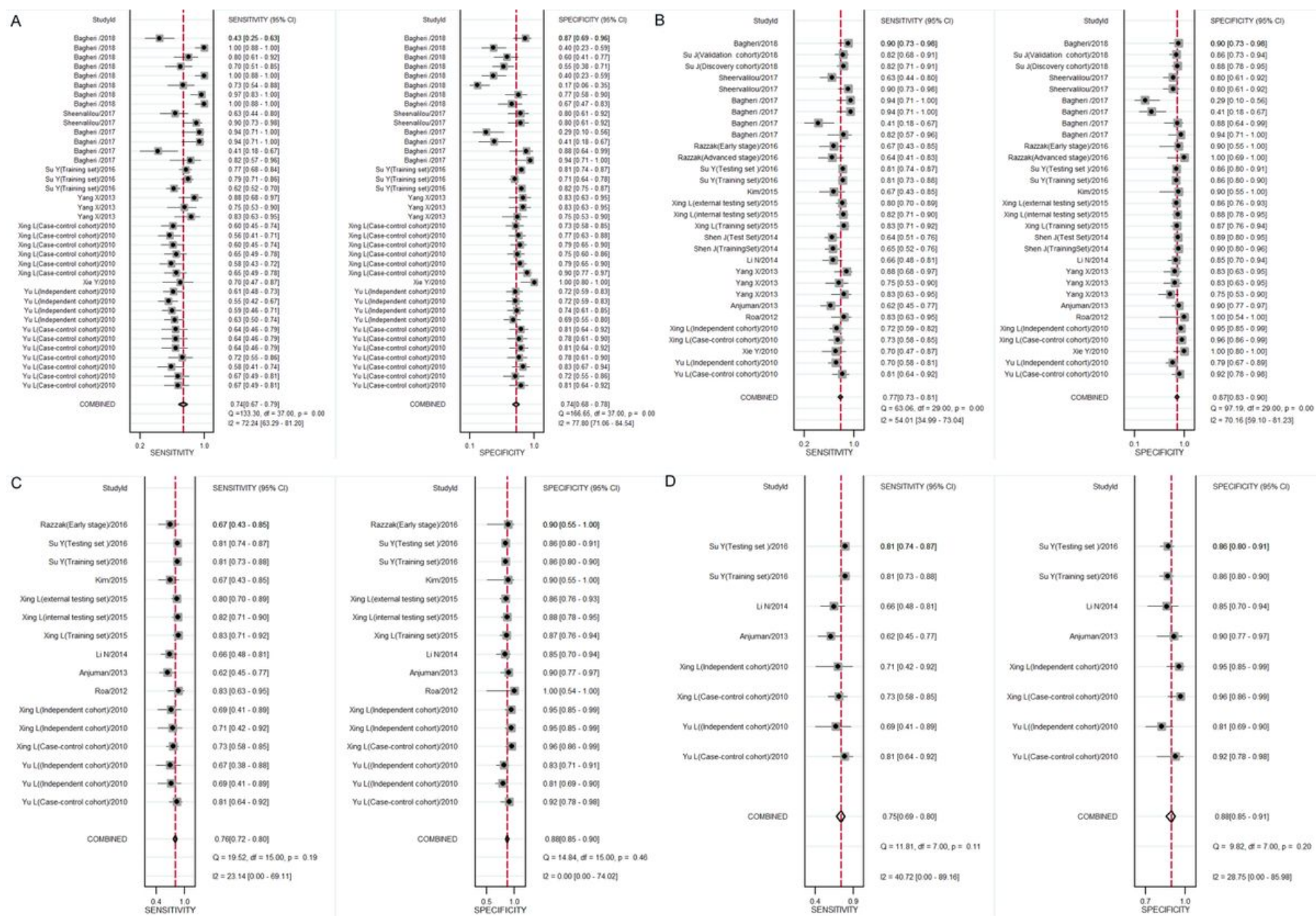

Figure 4

Forest plots of sensitivity and specificity for sputum miRNAs in the diagnosis of NSCLC by single miRNA (A), multiple miRNAs (B) and in stage I/II (C) and stage I disease (D). 

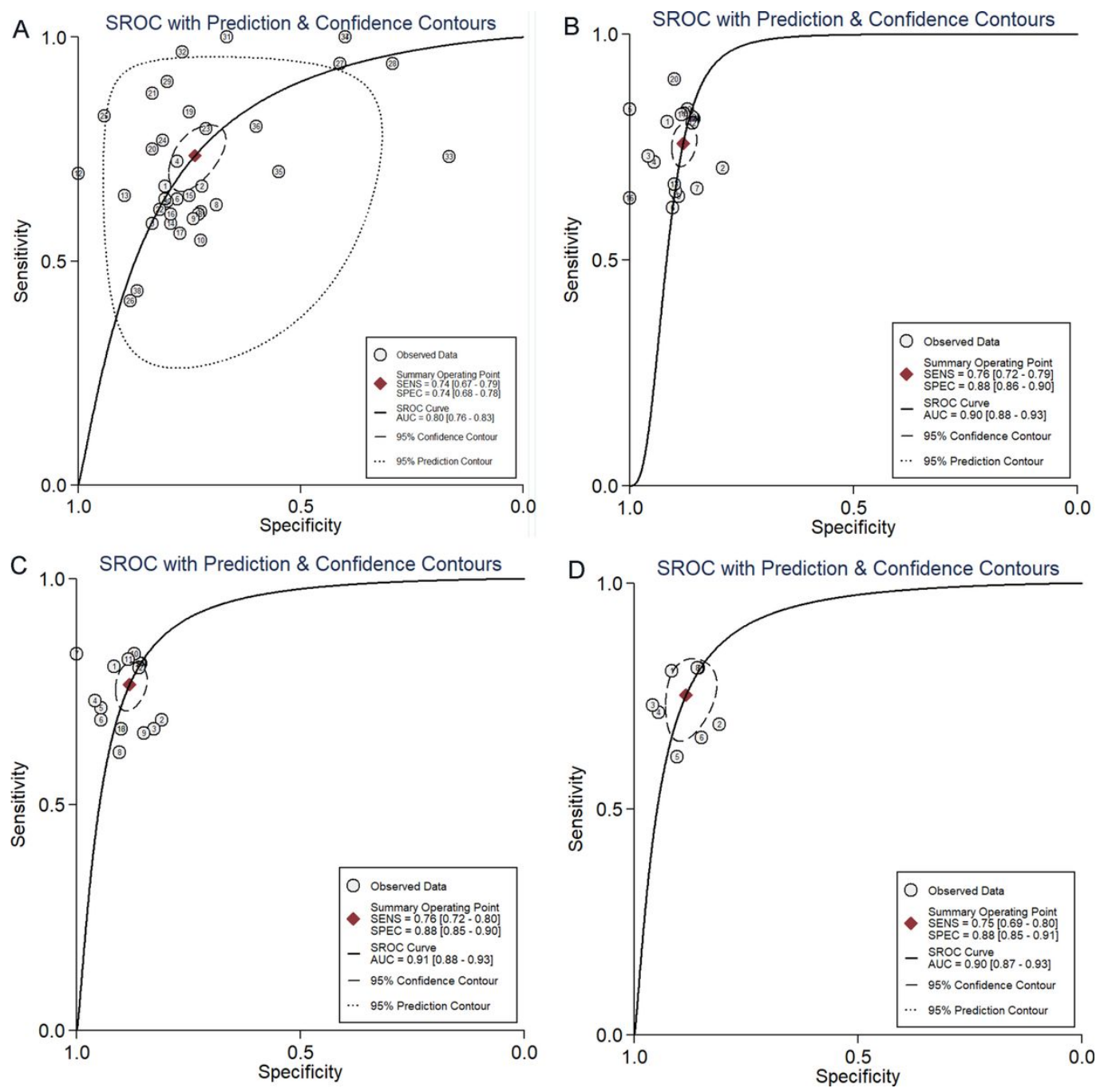

\section{Figure 5}

The summary receiver operator characteristic (SROC) curves of sputum miRNA for the diagnosis of NSCLC by single miRNA (A), multiple miRNAs (B) and in stage I/II (C) and stage I disease (D). 


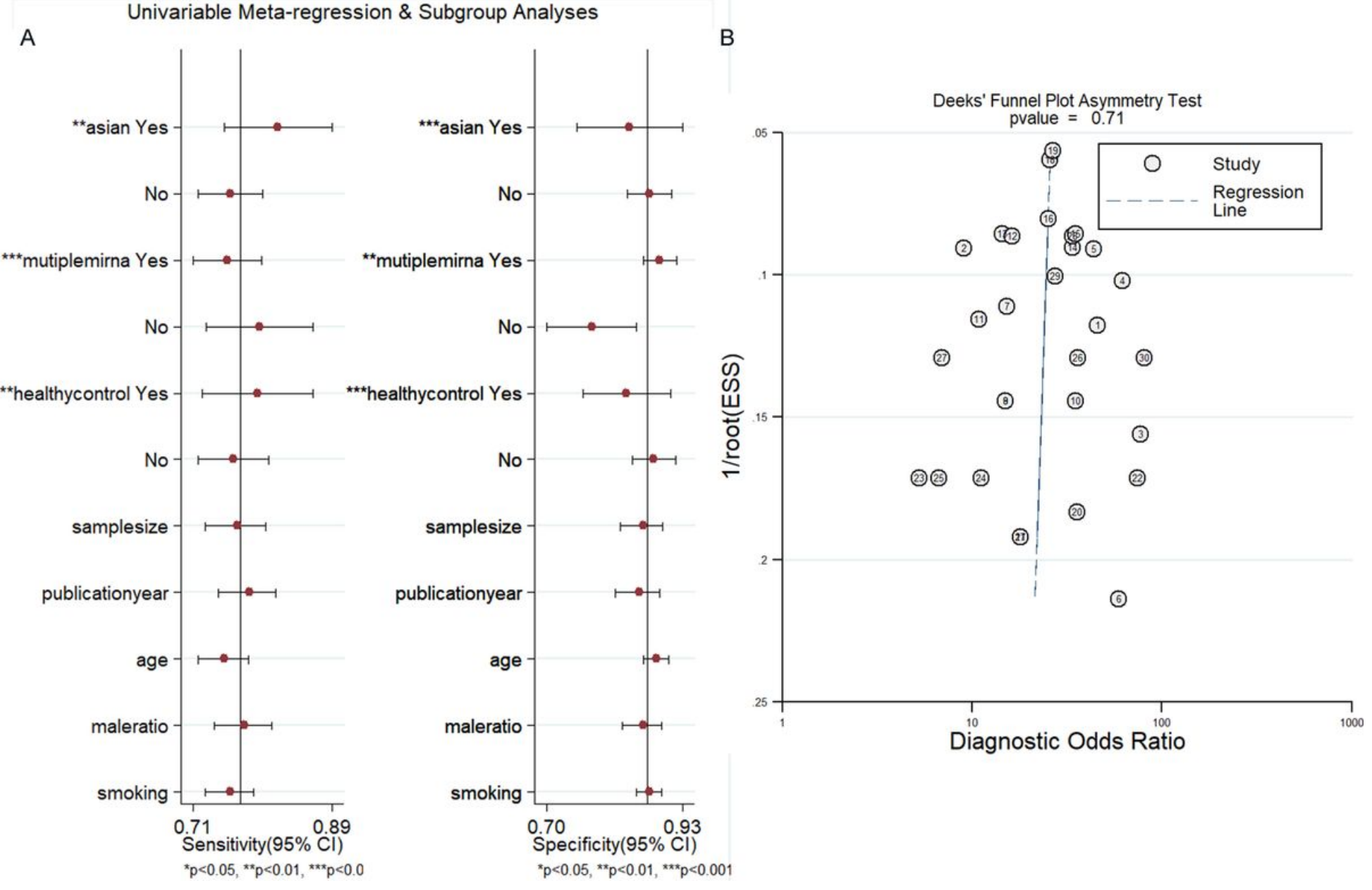

Figure 6

Forest plots of multivariable meta-regression analyses for sensitivity and specificity (A) and Deeks' linear regression test of funnel plot asymmetry (B) in overall population. 